\title{
Patterns in the distribution of juvenile corals and coral reef community structure in St. John, US Virgin Islands
}

\author{
Peter J. Edmunds* \\ Department of Biology, California State University, 18111 Nordhoff Street, Northridge, California 91330, USA
}

\begin{abstract}
There is increasing awareness that coral reefs exhibit a high degree of spatio-temporal variability, yet the processes that create these patterns are poorly known. In this study, benthic community structure and scleractinian recruitment on shallow reefs $(5 \mathrm{~m}$ depth) were quantified at 18 sites along $10 \mathrm{~km}$ of the coast of St. John, US Virgin Islands. The goal was to test 2 mechanisms that could create spatio-temporal variation - coral recruitment and early life-history events - by addressing 3 questions: (1) Is the percent cover of scleractinians correlated with the density of juvenile corals? (2) How is the density of juvenile corals affected by coral reef community structure? (3) What are the rates of mortality and growth of juvenile corals and how do they map onto the patterns of variation in juvenile density? Community structure was assessed as the percentage cover of the 4 major substratum components, and coral recruitment was estimated from the abundance of juvenile scleractinians. Temporal variation in the population of juvenile corals was examined over 4 yr (1994 to 1997) at 5 sites. The same 5 sites were used to assess the growth and survivorship of juvenile corals over 1 yr. Overall, the results demonstrate that there is a high degree of spatio-temporal variability in the shallow reefs of St. John. The community structure varied significantly among sites, and the density and taxonomic composition of juvenile corals varied significantly among sites and years. However, the density of juvenile corals was not correlated with the percentage cover of scleractinians, and the overall community structure did not explain a significant portion of the variation in the density of juvenile corals. Similar results were obtained when the juvenile corals were separated by reproductive mode (brooders vs spawners). The variation in density of juvenile corals was unlikely to have resulted from differential growth, as growth rates did not vary among sites. Additionally, mortality was not correlated with density of juvenile corals, although it did vary among sites. Together, these results suggest that the community structure of coral reefs is related only loosely to the contemporaneous distribution of juvenile corals and early life-history events (i.e., survivorship and growth of juvenile corals). Studies on larger spatial $(>10 \mathrm{~km})$ and temporal ( $>4 \mathrm{yr})$ scales probably are necessary to quantify the relationships between coral recruitment and coral community structure.
\end{abstract}

KEY WORDS: Juveniles $\cdot$ Scleractinians $\cdot$ Corals $\cdot$ Patterns $\cdot$ Variation $\cdot$ Reef Resale or republication not permitted without written consent of the publisher

\section{INTRODUCTION}

Spatio-temporal variability in community structure is a striking feature of marine environments (Levin 1992), but it can be difficult to identify the processes underlying these patterns. Recruitment is one mechanism with a central role in determining population densities (Caley et al. 1996) and creating variability (Connell \&

*E-mail: peter.edmunds@csun.edu
Keough 1985, Gaines \& Bertness 1992), yet there is no consensus regarding the relationships between the adult and recruiting populations (Caley et al. 1996). Quantifying these relationships is problematic in open marine systems because recruitment often follows a period of pelagic dispersal (Thorson 1950), when the larvae are difficult to identify (Coffroth \& Mulawka 1995) and hard to follow (Carlon \& Olson 1993). Moreover, the supply of pelagic larvae typically is highly variable in space and time (Gaines \& Bertness 1993, 
Keough \& Black 1996), and larvae remain inconspicuous when they first settle and metamorphose. Thus, it is challenging to quantify recruits on the appropriate scale, or even to identify them when they first appear in the community. Notwithstanding these problems there is evidence, notably from barnacles, that larval supply can affect patterns of settlement directly, as well as the distribution of adults (Gaines \& Roughgarden 1985). Most recruits also are affected strongly by post-settlement mortality, and this too can affect the distribution patterns of adults (Gosselin \& Qian 1997).

Coral reefs provide numerous examples of spatiotemporal variation in community structure (Jackson 1992, Karlson \& Hurd 1993, Aronson \& Precht in press). For example, coral reefs with high coral cover and richness are interspersed with areas of reduced coral cover (Edmunds \& Bruno 1996), and profound changes in community structure can occur on a time scale of decades (Knowlton 1992, Aronson \& Precht 1997) or months (Woodley et al. 1981). Such patterns are a result of differences in habitat and substratum type, as well as the history of physical and biological phenomena affecting extant communities (Connell 1978, Hughes 1989, Rogers 1993). Some of these phenomena have been studied extensively, including the damaging effects of physical, biological and anthropogenic disturbances (e.g., Grigg \& Dollar 1991, Ginsburg 1994), and the roles of coral reproduction and recruitment in reef growth (Rogers et al. 1984, Harrison \& Wallace 1990, Richmond 1997). However, the central question of how the distribution of adult corals is mediated by patterns of recruitment is poorly understood (Chiappone \& Sullivan 1996, Connell et al. 1997, Bak \& Meesters 1999).

Scleractinian recruitment also is characterized by large amounts of spatio-temporal variability (Wallace 1985, Babcock 1989, Dunstan \& Johnson 1998). This can be caused by a multitude of factors, including variation in the species composition of the reproductive population, the reproductive strategies (i.e., brooding vs spawning) of the coral species present (Harrison \& Wallace 1990), the fecundity of individual colonies (Hughes et al. in press), post-settlement mortality (Smith 1992, Dunstan \& Johnson 1998), and hydrographic conditions (Black et al. 1991). The larvae of spawning corals generally have a longer planktonic phase than larvae of brooding species (Richmond 1997), and therefore are more prone to the vagaries of larval dispersal (Keough \& Black 1996) and settlement (Wallace 1985) that typify open coral reef systems. Moreover, the discrepancies in time scales affecting coral colonies (years to centuries) and coral recruits (days to years) pose substantial problems in establishing cause-and-effect relationships spanning multiple decades. Thus, the profusion of factors that potentially affect scleractinian recruits may explain why some studies have found a relationship between the abundance of adult scleractinians and recruitment (Connell 1973, Johnson 1992, Chiappone \& Sullivan 1996), while others have not (Bak \& Engel 1979, Hughes et al. 1999).

The goal of this study was to determine how coral community structure is affected by the short-term population dynamics of juvenile scleractinians. The rationale behind this approach was the demographic axiom of a cause-and-effect relationship between recruitment and adult population structure (Gaines \& Roughgarden 1985, Caley et al. 1996), at least at some spatial and temporal scale, and the possibility that aspects of this relationship could be characterized with a correlative analysis. To attain this goal, I quantified the population dynamics of juvenile scleractinians (hereafter referred to as juvenile corals) and coral reef community structure at 18 sites along $10 \mathrm{~km}$ of the south coast of St. John, US Virgin Islands. Assuming that the null hypothesis of no spatial variation would be rejected for both coral reef community structure and juvenile corals (e.g., Edmunds \& Bruno 1996, Pandolfi 1996, Dunstan \& Johnson 1998), this study was designed to address 3 questions: (1) Is the percent cover of scleractinians correlated with the density of juvenile corals? In other words is there evidence of a stock-recruitment relationship, where the adults drive the number of recruits, or recruitment limitation where recruits drive the number of adults? (2) How is the density of juvenile corals affected by coral reef community structure? In other words do small-scale phenomena - such as the effects of substratum characteristics on the settlement of coral larvae (Carleton \& Sammarco 1987, Morse et al. 1988) and the role of competition in determining the success of newly settled corals (Birkeland et al. 1981) — scale up to an influence of overall community structure on the density of juvenile corals? (3) What are the rates of mortality and growth of juvenile corals, and how do these map onto the patterns of variation in juvenile density? A significant correlation between the density of juvenile corals and either mortality or growth would provide indirect evidence of early life-history events affecting the distribution of juvenile corals.

These questions were addressed primarily using results pooled across coral taxa. This was necessary because meaningful analyses for each coral taxon (i.e., genus or species) were precluded by large numbers of near-zero values for both mean percent cover and median densities of juveniles at each site. Although these problems were avoided by pooling across taxa, this solution trades the advantages of a larger-scale study (Levin 1992) and statistical rigor against the benefits of species-level analyses. There still is much to learn about individual coral species, particularly about their demographics (Bak \& Meesters 
1999), but it is difficult to complete the appropriate large-scale analyses of individual species in the Caribbean. This is because shallow reefs in the Caribbean increasingly are characterized by low coral cover, and very large areas are required to sample effectively at the species level.

In the present study, juvenile corals were defined as colonies between 2 and $40 \mathrm{~mm}$ diameter (cf. Bak \& Engel 1979, Rogers et al. 1984), and were quantified instead of newly settled corals because the latter are difficult to detect on natural substrata (Babcock \& Mundy 1996). Such a liberal definition of a juvenile includes colonies of various ages and demographic stages. For example, growth rates of 1 to $3 \mathrm{~mm} \mathrm{mo}^{-1}$ (Bak \& Engel 1979, Van Moorsel 1988) suggest that the juveniles in the present study were $\sim 1$ to 40 mo old and, as sexual maturity can be reached at a size of $4 \mathrm{~cm}^{2}$ (e.g., Favia fragum and Siderastrea radians: Soong 1993), some probably were adults rather than juveniles. Regardless of these limitations, corals $\leq 40 \mathrm{~mm}$ in diameter are young with regard to the longevity of most scleractinian colonies, and therefore should provide insight into the processes linking early life-history stages to coral reef community structure (Bak \& Meesters 1999).

\section{MATERIALS AND METHODS}

Study sites and overall approach. The coast of St. John is surrounded by fringing coral reefs (Rogers \&
Teytaud 1988, Edmunds et al. 1990), which in shallow water ( $<6 \mathrm{~m}$ depth) often consist of boulder fields with low scleractinian cover $(<13 \%)$ and large amounts of algal turf ( $>26 \%$ cover). On deeper reefs $(>8 \mathrm{~m}$ ) scleractinian cover ranges from $\sim 10$ to $40 \%$ and is dominated by Montastraea annularis (Rogers et al. 1997, P.J.E. unpubl. data).

Eighteen sites were chosen arbitrarily along $10 \mathrm{~km}$ of the south coast of St. John in order to quantify spatial variation in community structure and the distribution of juvenile corals (Fig. 1). All sites were at $5 \mathrm{~m}$ depth, and were surveyed in June 1994 (10 sites) or June 1995 (8 sites). Community structure was quantified using photoquadrats, and juvenile corals were counted in situ. To determine whether the distribution of juveniles was influenced by early life-history events (i.e., mortality and growth), tagged corals were monitored for $1 \mathrm{yr}$.

Community structure and abundance of juvenile corals. Community structure was quantified using $\sim 17$ photoquadrats $\left(0.25 \mathrm{~m}^{2}\right)$ positioned randomly along a $40 \mathrm{~m}$ transect at the $5 \mathrm{~m}$ depth contour. Photographs were taken with a Nikonos ${ }^{\mathrm{TM}} \mathrm{V}$ camera mounted on a frame and fitted with a $28 \mathrm{~mm}$ lens and strobes. Color transparencies were analyzed by overlaying the projected image with a grid of 200 random dots and counting the dots falling on each substratum type to obtain percentage cover. Objects as small as $1 \mathrm{~cm}$ diameter were resolved with this technique. Scleractinians, macroalgae, invertebrates (defined as the pooled cover of sponges, gorgonians, Palythoa caribaeorum and

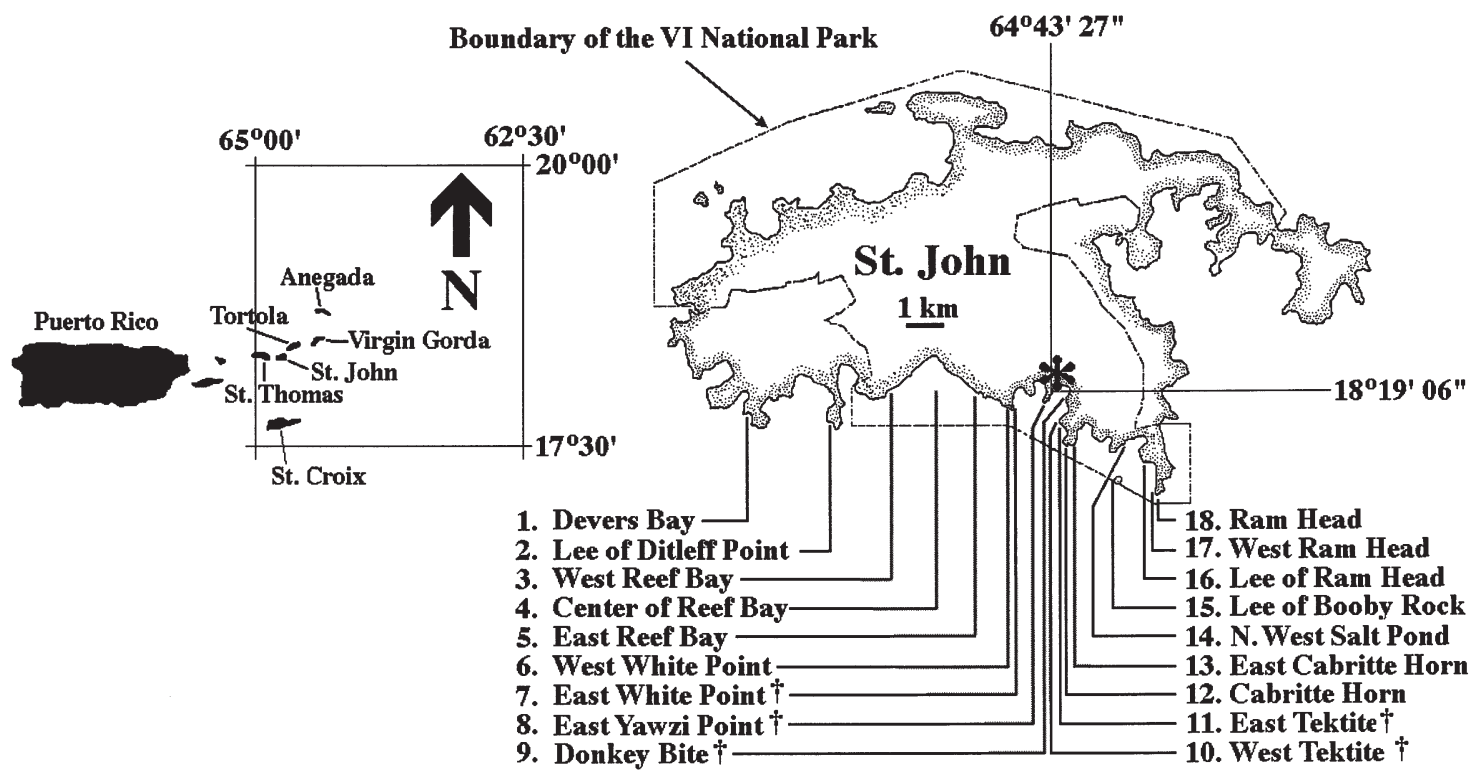

Fig. 1. Location of study sites (1 through 18) on St. John, and location of St. John within the Virgin Islands (modified from Rogers \& Teytaud 1988). Dashed line around St. John marks boundary of the Virgin Islands National Park. * Site of the Virgin Islands Environmental Resources Station, $\uparrow$ study sites used for assessment of growth and mortality of juvenile corals 
Millepora spp.) and hard substratum were quantified because they accounted for the majority of the substratum (>94\% at all sites except for Site 9 [67\%]). Hard substratum was defined as vacant hard substratum and algal turf, because these categories could not be distinguished reliably in photographs.

Juvenile corals were censused using 40 quadrats $\left(0.25 \mathrm{~m}^{2}\right)$ positioned randomly along the same $40 \mathrm{~m}$ transects used in the assessment of community structure at the 18 sites. Quadrats were surveyed by parting algae and removing sediment to see corals as small as $2 \mathrm{~mm}$ diameter (1 polyp). Juveniles were defined as colonies $\leq 40 \mathrm{~mm}$ in diameter that were attached to the substratum and did not have the fractured surface characteristic of asexual recruits (Highsmith 1982). Corals were identified to species where possible, and to genus where they lacked features allowing congeners to be distinguished; hereafter, genera and species of juvenile corals are referred to as 'taxa'. Spatial variation in the distribution of juvenile corals was examined through a comparison of density (pooled across taxa) among sites. Data were pooled from 10 sites in 1994 and 8 sites in 1995 to allow sites to be compared on a scale of $10 \mathrm{~km}$. To determine whether recruitment varied between 1994 and 1995, 2 of the sites (10 and 11) were surveyed in both years and the density of juvenile corals compared. These 2 sites together with 3 others (Sites 7, 8 and 9) also were surveyed in 1996 and 1997 to obtain a more comprehensive description of temporal variation in the abundance of juvenile corals.

As pooling the juvenile corals across taxa obscures patterns occurring at the level of functional groups or taxa, among-site comparisons also were completed for brooders versus spawners and for individual taxa when sample sizes were sufficient. Corals were separated by reproductive mode because this discerns ecologically distinct groups differing in life-history characteristics (after Hughes et al. 1999). For example, in addition to the mode of fertilization, brooders and spawners might differ in distribution because of the possibly short time between larval release and settlement of brooders (Richmond 1997). Analysis by reproductive mode was completed only for taxa that could be identified as brooders or spawners with certainty (according to Fadlallah 1983, Soong 1991, Smith 1992, van Veghel 1993, Richmond 1997).

Mortality and growth of juvenile corals. To quantify the mortality and growth of juvenile corals, corals were monitored over 1 yr at 5 sites. In June 1996 juveniles were selected haphazardly along a transect line placed at $5 \mathrm{~m}$ depth, and were permanently marked with aluminum tags that were epoxied to the adjacent substratum. Approximately 100 colonies from several taxa were tagged at each site, and their maximum and minimum diameters were recorded with calipers $( \pm 0.1 \mathrm{~mm})$. Tags were relocated in June 1997 and colonies scored as alive or dead (dead in the growth position or missing), and the sizes were measured for living colonies. The percentage of tagged corals that were censused in both years and were dead in 1997 was used as a measure of mortality, and the change in mean diameter was used as a measure of growth.

Statistical analyses. Statistical analyses were completed using Systat 5.2. Community structure was compared among sites using a 1-way MANOVA to determine whether an overall site effect existed; when a site effect was detected, the 4 substratum categories were then compared among sites using univariate, 1-way ANOVA. Bonferonni adjustments $\left(\alpha^{\prime}\right)$ were used to detect significant effects with an overall Type I error rate of 0.05 (Tabachnick \& Fidell 1996). As the community structure was quantified as percent cover, data were arcsine-transformed (Sokal \& Rohlf 1995) prior to testing for conformation to the assumptions of each analysis.

The abundance of juvenile corals was skewed positively (as expected: Bak \& Meesters 1999), and normality could not be restored with transformations. Therefore, among-site comparisons were completed with a Kruskal-Wallis test (for density) and a $\chi^{2}$-contingency table (for relative abundance of taxa). To determine whether the reproductive strategy affected distribution patterns, the density of juveniles of brooders and spawners were compared among sites with a KruskalWallis test $(H)$. The comparison of juvenile density among 18 sites required the pooling of data from 1994 and 1995. The densities of juvenile corals at Sites 10 and 11 were compared between these years with Mann-Whitney $U$-tests to determine whether density varied. Densities also were compared among years over 1994 to 1997 at 5 sites ( 7 through 11) to examine longer-term variation in the population of juveniles; this analysis was completed with Kruskal-Wallis tests. The abundances of the common taxa were compared among years using a $\chi^{2}$-contingency table to determine whether the relative abundance of individual taxa varied over time.

A correlation analysis was used to quantify the association between the median density of juvenile corals and the mean percent cover of scleractinians. A multiple regression was used to further resolve the influence of the community structure on the density of juvenile corals. These analyses were completed to determine which component, if any, of the benthic community was influential in determining the density of juvenile corals. Two multiple regressions were carried out. First, a multiple regression was completed using the median density of juvenile corals as the dependent variable, and the mean percent cover of scleractinians, 
macroalgae, invertebrates and hard substratum as independent variables. A second multiple regression was completed using the median density of the juveniles of brooding species as the dependent variable, and the same independent variables as in the first analysis. As the median density of juveniles of spawning species was zero at most sites, these data were not analyzed with multiple regression. Each of the 18 sites was treated as a statistical replicate in the correlation and multiple-regression analyses, and the median density of juvenile corals was used because their distribution was not normal.

First-, second- and third-order spatial autocorrelation analyses were used to determine whether nearby sites were more similar to one another than to more distant sites. Significance was assessed with a Bonferonni adjustment $(\alpha / 3=0.017)$; no additional autocorrelations were completed because of the elevated risks of Type I error. Autocorrelation analyses were completed using the mean percent cover for each of the 4 components of the benthic community, as well as the median density of juveniles corals, pooled across taxa. A significant autocorrelation would suggest similarity in community structure among nearby sites, for example because they occupy the same habitat and/or are exposed to a similar supply of pelagic larvae.

The mortality of juvenile corals over 1996 to 1997 was compared among sites with a $\chi^{2}$-contingency table (site $\times$ [dead vs alive]), first with the data pooled by taxon and second, for each of the common taxa. To determine whether the density of juveniles was affected by their mortality, the relationship between their density in 1997 and their mortality over 1996 to 1997 was examined with correlation analysis using sites $(n=5)$ as replicates. The growth rates of juveniles also were compared among sites to determine whether this could contribute to among-site differences in the density of small corals. ANCOVA was used to compare growth rates (dependent variable) among sites (fixed factor) for each of the common taxa using size in 1996 as a covariate.

\section{RESULTS}

\section{Community structure and abundance of juvenile corals}

The community structure at the 18 sites was characterized by a low cover of scleractinians (0.9 to $12.3 \%$ ) and large amounts of hard substratum (28.9 to $90.7 \%$ cover). There was a variable cover of macroalgae $(0.1$ to $22.3 \%$ ), as well as sponges, gorgonians, Palythoa caribaeorum and Millepora spp. combined (a total of 1.1 to $48.3 \%$; Fig. 2). Seventeen species of scleractini- ans were found, and the most common (between 0.1 and $11 \%$ cover) were Montastraea annularis (sensu Weil \& Knowlton 1994), M. cavernosa, Siderastrea radians, Agaricia spp., Diploria strigosa, Porites porites and $P$. astreoides. MANOVA revealed that the community structure was significantly different among sites (Wilk's $\lambda=0.221, \mathrm{~F}=7.884$, $\mathrm{df}=68,114, \mathrm{p}=0.001$ ), and subsequent univariate ANOVAs $\left(\alpha^{\prime}=0.014\right)$ showed that they differed significantly in the cover of scleractinians $(F=2.950, \mathrm{df}=17,294, \mathrm{p}<0.001$, power $>0.84)$, macroalgae $(F=9.451$, df $=17,294, \mathrm{p}<0.001$, power $>$ $0.84)$, sponges, gorgonians, $P$. caribaeorum and Millepora spp. combined $(F=15.260$, df $=17,294, \mathrm{p}<0.001$, power $>0.84)$, and hard substratum $(F=14.028, \mathrm{df}=$ $17,294, \mathrm{p}<0.001$, power $>0.84)$. None of the autocorrelations for each of the 4 components of the community structure were significant $(\mathrm{r} \leq 10.383 \mathrm{l}, \mathrm{n}=18$ sites, $\mathrm{p}>0.050$ ). Thus, the variation in community structure was independent among sites.

The censuses of juvenile corals revealed between 0 and 53 corals per $0.25 \mathrm{~m}^{2}$ in the 720 quadrats surveyed $\left(180 \mathrm{~m}^{2}\right)$, and included representatives of 15 genera and at least 17 species. The juvenile coral population probably contained $>17$ species, because some genera contained $>1$ species but these could not be resolved when the colonies were small. The majority of juveniles (97\%, n = 2677) were Porites spp. (33\%), Agaricia spp. (19\%), Favia fragum (18\%), Siderastrea radians $(17 \%)$, S. siderea $(5 \%)$ or Diploria spp. (5\%), with the remaining taxa each representing $<0.70 \%$ of the corals. Most of the juvenile corals (53 to $91 \%$ at each site) belonged to brooding species, with a smaller number belonging to spawning species (2 to $29 \%$ at each site), or species with an unknown reproductive strategy ( 2 to $37 \%$ at each site).

The abundance of juvenile corals did not vary significantly between 1994 and 1995 at Site 10 (MannWhitney $U=960.5, \mathrm{n}_{1} \& \mathrm{n}_{2}=40, \mathrm{p}=0.118$ ) or Site 11 $\left(U=627.5, \mathrm{n}_{1} \& \mathrm{n}_{2}=40, \mathrm{p}=0.092\right)$, and there was no significant difference in the relative abundance of the 6 most common taxa (Porites spp., Agaricia spp., Favia fragum, Siderastrea radians, S. siderea or Diploria spp.) between years $(6 \times 2$ contingency table; Site 10: $\chi^{2}=3.007, \mathrm{df}=5, \mathrm{p}=0.699$; Site 11: $\chi^{2}=7.007, \mathrm{df}$ $=5, \mathrm{p}=0.220$ ). However, over a longer time scale (1994 to 1997), density varied significantly among years at Sites 10 and 11 ( $4 \mathrm{yr}$ of data; $H \geq 13.256, \mathrm{n}_{1-4}$ $=40, \mathrm{p} \leq 0.004$ ) and Sites 8 and 9 ( $3 \mathrm{yr}$ of data; $\mathrm{H} \geq$ 9.329, $\mathrm{n}_{1-3}=40, \mathrm{p} \leq 0.009$ ), but not at Site 7 (3 yr of data; $H=1.105, \mathrm{n}_{1-3}=40, \mathrm{p}=0.576$ ) (Fig. 3). A single analysis among years for all sites was not completed because there were no data for 1995 from Sites 7, 8 and 9. The relative abundance of the 5 most common taxa in the multi-year analysis (Porites spp. Agaricia spp., F. fragum, Siderastrea spp. and Diploria spp.; the 

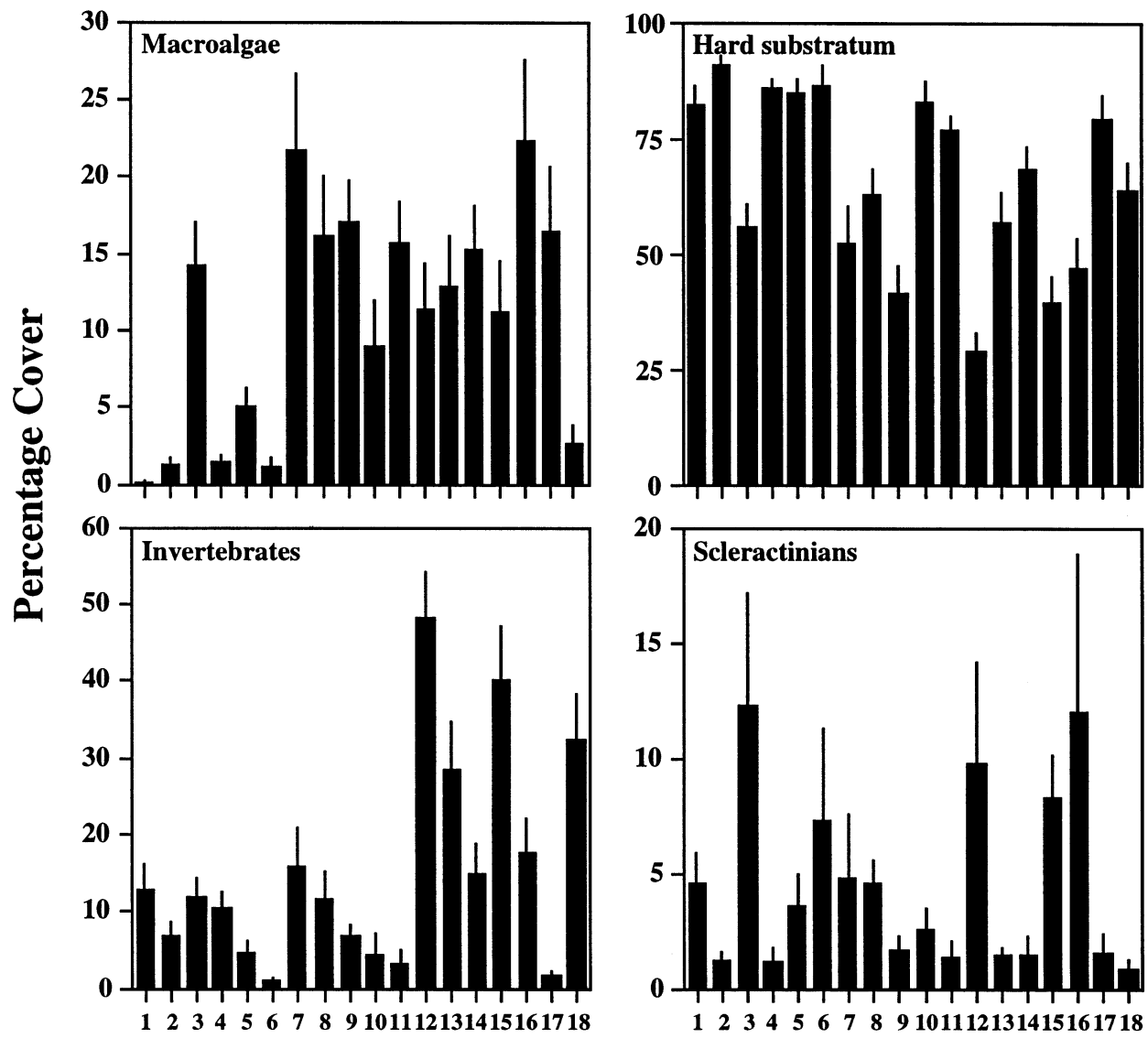

\section{Site}

Fig. 2. Benthic community structure at 18 sites along the south coast of St. John. Mean + SE shown for untransformed data $(\mathrm{n}=$ 15 to 18 for all sites). 'Hard substratum' includes algal turf and vacant surfaces, as these could not be distinguished in photographs. 'Invertebrates' includes pooled cover of sponges, gorgonians, Palythoa caribaeorum and Millepora spp. Site numbers as in Fig. 1

2 species of Siderastrea were not scored separately in 1996 and 1997) differed significantly among years at Sites 10 and $11(5 \times 4$ contingency table: $\chi^{2} \geq 79.103, \mathrm{df}=12, \mathrm{p}<0.001$ ) and Sites 7 and $8(5 \times 3$ contingency table, $\chi^{2} \geq 22.337, \mathrm{df}=8, \mathrm{p}<0.010$ ), but not at Site $9(5 \times 3$ contingency table: $\chi^{2}=11.482, \mathrm{df}=8, \mathrm{p}=0.176$ ). Thus, although the density and taxonomic composition of the population of juvenile corals generally varied among years, data from Sites 10 and 11 show that there was no significant variation between June 1994 and June 1995 (Fig. 3). Therefore, the censuses completed in June 1994 and June 1995 were pooled to examine variation in the population of juvenile corals among 18 sites.

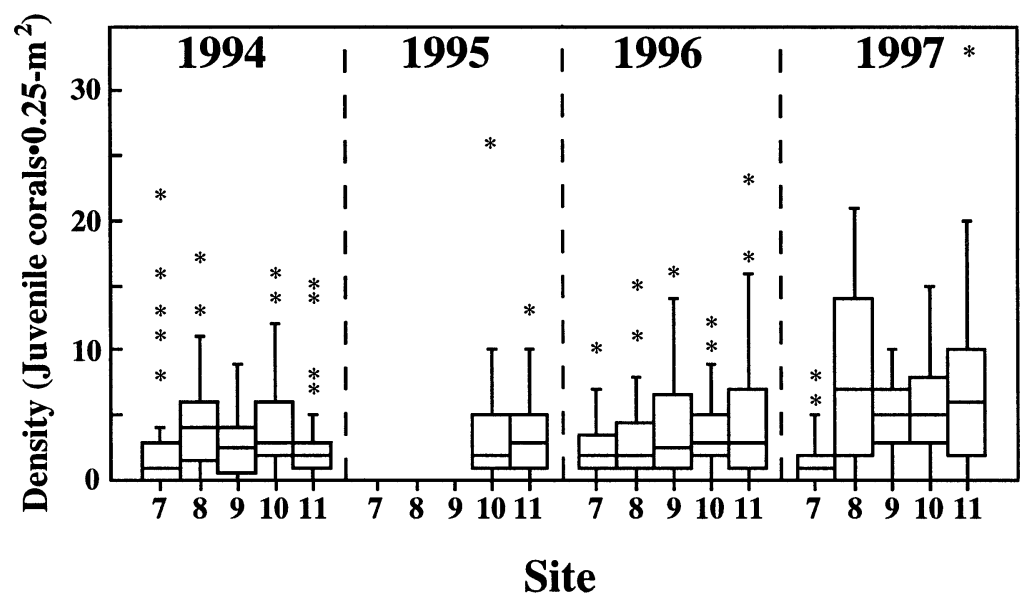

Fig. 3. Box plots of density of juvenile corals at 5 sites over 4 yr (sites numbered in Fig. 1). Data were not collected at Sites 7, 8 and 9 during 1995; $\mathrm{n}=40$ quadrats for all sites. Horizontal line inside each box $=$ median; top and bottom lines of boxes = upper and lower quartiles, respectively; vertical bars link nearest data within 1.5 interquartile ranges of the upper and low quartiles; *Data $>1.5$ interquartile ranges away from respective box 


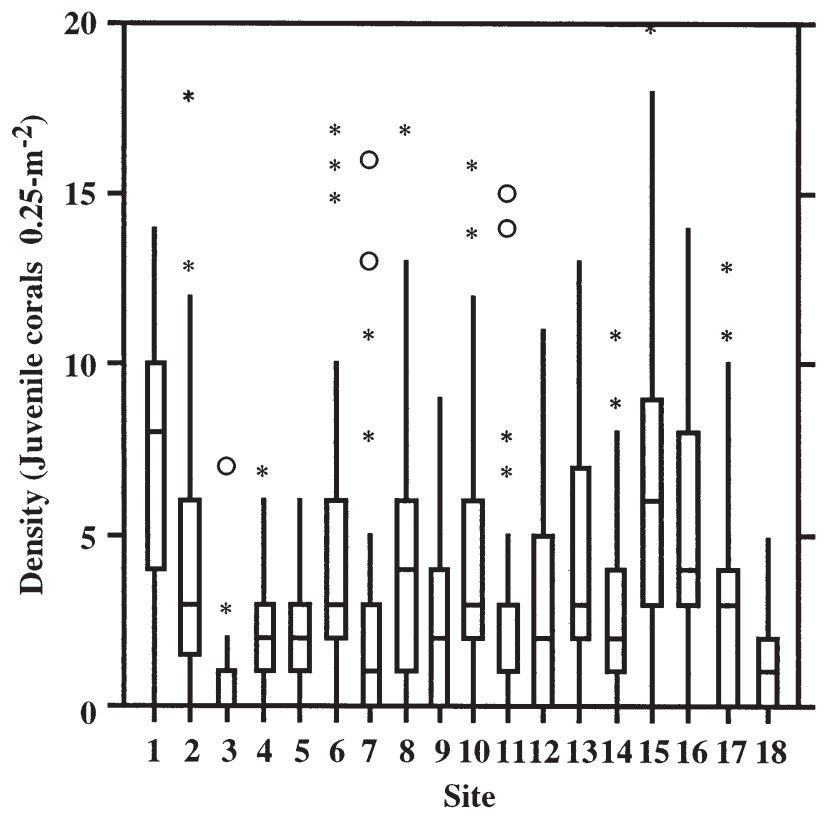

Fig. 4. Box plots of density of juvenile corals at each of the 18 sites ( $\mathrm{n}=40$ quadrats for each site, located randomly along a $40 \mathrm{~m}$ transect in 1994 or 1995). Horizontal line inside each box $=$ median top and bottom lines of boxes = upper and lower quartiles, respectively; vertical bars link nearest data within 1.5 interquartile ranges of the upper and low quartiles. * Data $>1.5$ interquartile ranges away from respective box; O: data $>3.0$ interquartile ranges away from respective box. Two data points are not shown: 22 juvenile corals $0.25 \mathrm{~m}^{-2}$ for Site 7 , and 53 juvenile corals $0.25 \mathrm{~m}^{-2}$ for Site 2. Site numbers as in Fig. 1

The median density of juvenile corals ranged between 0 and 8 juvenile corals $0.25 \mathrm{~m}^{-2}$ (Fig. 4), and sites $\sim 1 \mathrm{~km}$ apart displayed median densities differing as much as 5-fold (e.g., Sites 15 vs 18). Overall, the density of juvenile corals differed significantly among the 18 sites $\left(H=170.655, \mathrm{n}_{1-18}=40, \mathrm{p}<0.001\right)$, and the sites displayed significant differences in the relative abundance of the 6 most common taxa (Porites spp., Agaricia spp., Favia fragum, Siderastrea radians, $S$. siderea or Diploria spp.) $\left(6 \times 18\right.$ contingency table, $\chi^{2}=$ 1136.457, df $=85, \mathrm{p}<0.001$ ). Significant site effects also were found when the juveniles corals were analyzed separately as brooders $\left(H=146.274, \mathrm{n}_{1-18}=40\right.$, $\mathrm{p}<0.001)$ and spawners $\left(H=96.120, \mathrm{n}_{1-18}=40\right.$, $\mathrm{p}<0.001)$. None of the autocorrelations for the median density of all juvenile corals were significant $(\mathrm{r} \leq$ $|0.239|, \mathrm{n}=18$ sites, $\mathrm{p}>0.050$ ). Thus, not only was the density of juvenile corals highly variable, but also it was independent among sites.

The percent cover of scleractinians at the 18 sites was not correlated significantly with the density of juvenile corals $(r=0.015, n=18, p=0.953)$. Additionally, multiple-regression analysis demonstrated that the median density of juvenile corals was unrelated to the percent cover of the quantified components of the community structure $(F=0.369, \mathrm{df}=4,13, \mathrm{p}=0.826)$. A similar result was obtained for the density of juveniles of brooding taxa and the community structure $(F=$ 0.922 , $\mathrm{df}=4,13, \mathrm{p}=0.481$ ). Thus, the present analysis of coral reefs at 18 sites failed to detect a relationship between community structure and the distribution of juvenile corals.

\section{Mortality and growth of juvenile corals}

In 1996, 532 corals ranging in size from 3.0 to $35.5 \mathrm{~mm}$ diameter were tagged at 5 sites. Corals from 8 genera were tagged, although $>95 \%$ were Agaricia spp., Favia fragum, Porites spp. Siderastrea radians, or S. siderea. In 1997, 396 were found again (Fig. 5); 250 were alive, 146 were dead or missing and presumed dead, and 136 were not scored because their tags were not found. The mortality rate pooled across taxa and sites was $37 \% \mathrm{yr}^{-1}$, but ranged between 24 and $57 \%$ $\mathrm{yr}^{-1}$ among sites (Fig. 5). The mortality rate differed significantly among sites for all taxa combined $(2 \times 5$ contingency table; $\chi^{2}=21.414$, df $=4, \mathrm{p}<0.001$ ), but only for Favia fragum $\left(2 \times 5\right.$ contingency table; $\chi^{2}=$ $21.414, \mathrm{df}=4, \mathrm{p}<0.001$ ) when analyzed by taxon (the mortality rate of all other taxa were not significantly different among sites, $\mathrm{p} \geq 0.191$ ). When pooled across site, the mortality rates were $50 \% \mathrm{yr}^{-1}$ for Agaricia spp., $48 \% \mathrm{yr}^{-1}$ for $F$. fragum, $27 \% \mathrm{yr}^{-1}$ for Porites spp., $35 \% \mathrm{yr}^{-1}$ for $S$. siderea, and $23 \% \mathrm{yr}^{-1}$ for S. radians. Overall, the number of corals found alive or dead differed significantly among taxa $(2 \times 5$ contingency table; $\chi^{2}=21.680, \mathrm{df}=4, \mathrm{p}=0.002$ ). Thus, whether or not the tagged corals died between 1996 and 1997 depended on the taxon and location, although the location effect was a result largely of among-site differences in mortality of $F$. fragum. Although there were significant site effects for juvenile mortality over 1996 to 1997 , and the median density of all small corals (i.e., pooled across taxa) in 1997 (Fig. 3, Kruskal Wallis test, $\left.H=37.390, \mathrm{n}_{1-4}=40, \mathrm{p}<0.001\right)$, there was no significant relationship between the two $(r=-0.468, n=5, p=$ 0.426).

The growth rates of the tagged corals were low, and many corals shrank. The changes in diameter ranged from -23.0 $\mathrm{mm} \mathrm{yr}^{-1}$ (i.e., a reduction in size) for Siderastrea radians, to $19.7 \mathrm{~mm} \mathrm{yr}^{-1}$ for Dendrogyra cylindrus. The overall mean growth rate was $2.1 \pm 0.4 \mathrm{~mm} \mathrm{yr}^{-1}$ $( \pm \mathrm{SE}, \mathrm{n}=250)$. As growth rates were inversely related to initial size, they were compared among sites and taxon with ANCOVA. The slopes of the growth versus initial size relationships for all the corals (pooled by taxon) were not significantly different among sites 


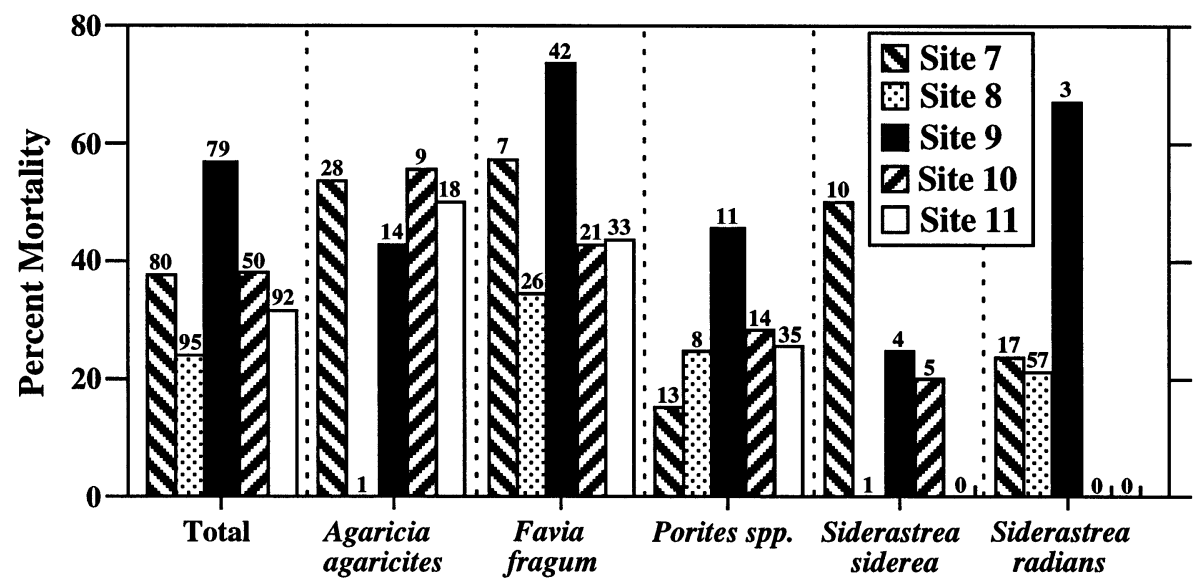

Fig. 5. Annual mortality rates of juvenile corals tagged at 5 sites and censused in June 1996 and June 1997; values are shown for juvenile corals pooled across taxa (Total) as well as the 5 taxa that were tagged most frequently. Approximately 100 corals were tagged at each site in 1996, but only those corals adjacent to the tags that were relocated in 1997 were included in the present analysis; sample sizes shown above each bar. Site numbers as in Fig. 1

$(F=2.047, \mathrm{df}=4,240, \mathrm{p}=0.089)$, and the growth rates (i.e., elevations) were indistinguishable statistically among sites $(F=0.301$, df $=4,244, \mathrm{p}=0.254)$. Similar results were obtained when the growth rates were analyzed by taxon using the 4 taxa that were tagged frequently and found at multiple sites ( $\mathrm{n}=35$ to 66 per species). The slopes of the growth versus initial size relationships did not differ significantly among sites ( $p>0.144$ ), and the elevations were statistically similar among sites for Agaricia spp. (4 sites; $F=1.279 \mathrm{df}=$ $3,29, \mathrm{p}=0.300$ ), Favia fragum (5 sites; $F=0.253$, $\mathrm{df}=4,53, \mathrm{p}=0.907)$, Porites spp. (5 sites; $F=0.797, \mathrm{df}=$ $4,60, \mathrm{p}=0.532$ ), and $S$. radians (2 sites; $F=0.095$, $\mathrm{df}=1,54, \mathrm{p}=0.759$ ). Thus, the growth-size relationships were similar for these 4 taxa and their growth rates were statistically indistinguishable among sites.

\section{DISCUSSION}

This study demonstrates that the shallow reefs of St. John are highly variable across both spatial and temporal scales. On a spatial scale of $10 \mathrm{~km}$, community structure and the population of juvenile corals varied significantly among sites, and on a temporal scale of $4 \mathrm{yr}$ the population of juvenile corals varied significantly among sampling intervals. However, there were no statistically significant relationships between coral reef community structure and the dynamics of juvenile corals, and community structure (percent cover of corals, macroalgae, hard substrata and invertebrates) was unrelated among sites (i.e., there was no spatial autocorrelation). Thus, there was no evidence of (1) a stock-recruitment relationship or recruitment limitation for scleractinian corals, (2) the scaling-up of pro- cesses, such as species-species interactions, to an effect of community structure on the population of juvenile corals, or (3) early life-history events affecting the distribution of juvenile corals. The poor association between coral reef community structure and the contemporaneous population of juvenile corals appears to be inconsistent with the demographic axiom that adult populations are supported by recruitment (Ebert 1999). However, this is probably a consequence of the spatiotemporal scale of the investigation, and underscores the need for longer-term ( $>4 \mathrm{yr}$ ) studies over larger spatial scales $(>10 \mathrm{~km})$ to quantify the processes that create kilometer-scale patterns in coral reef communities. Such studies also might allow an analysis of the scale-dependency of the relationship between adult and juvenile corals, specifically testing how (or whether) reef-level effects (i.e., this study) relate to species-level effects.

Spatio-temporal variability is characteristic of both extant and fossil coral reefs (Pandolfi 1996, Karlson \& Cornell 1998, Hughes et al. 1999, Aronson \& Precht 1995, in press). Thus, coral reefs routinely exhibit striking differences in community structure among sites throughout the Caribbean and Pacific (Connell 1973, Porter \& Meier 1992, Edmunds \& Bruno 1996, Pandolfi 1996), and the recruitment of reef-associated taxa including scleractinians, octocorals, and fishes typically is highly variable among sites and sampling periods (Yoshioka 1996, Tolimieri et al. 1998, Hughes et al. 1999). Such variability has important implications for the study of coral reef ecology and the management of coral reef ecosystems. For example, the patchiness in habitat availability and community structure meet the conditions necessary for a metapopulation analysis (Hanski 1997) that might provide new insight into the 
dynamics of coral reef communities (Jackson et al. 1997, Mumby 1999). A metapopulation analysis might help to explain the consequences of degraded reefs, such as those in Jamaica (Hughes 1994) and the Florida Keys (Porter \& Meier 1992), occurring adjacent to patches of reef that are less degraded (e.g., Edmunds \& Bruno 1996). Additionally, spatially or temporally rare and/or extreme events could provide important mechanisms (sensu Gaines \& Denny 1993) creating variation in community structure, including areas of anomalous coral cover or species composition. Thus, severe storms can denude tracts of reef while leaving nearby areas intact (Bythell et al. 1993, Connell et al. 1997), and it is possible that peaks in the spatio-temporal mosaic of coral recruitment could generate persistent signals in community structure (Hughes \& Connell 1999, Hughes et al. 1999). Although scleractinian populations are thought to be characterized by long-lived colonies of varying ages rather than by successful cohorts (Hughes 1994), evidence from gorgonian populations in Puerto Rico demonstrates that shortterm, high rates of recruitment can have a large effect on population structure (Yoshioka 1996). The periodic occurrence of successful cohorts of juvenile corals in St. John might explain, in part, why coral community structure and the dynamics of juvenile corals appear to be uncoupled. For example, present-day coral populations might reflect successful recruitment that occurred years or decades earlier.

The absence of a relationship between the distribution of adult and juvenile corals has been reported elsewhere in the Caribbean (Bak \& Engel 1979), but is in contrast to the situation in the Florida Keys, where the distributions of adult and juvenile corals are positively related (Chiappone \& Sullivan 1996). This discrepancy may reflect the low variation in coral recruitment in the Florida Keys (mean values of 1.2 to 3.7 juveniles per $0.25 \mathrm{~m}^{2}$ ) (Chiappone \& Sullivan 1996) compared to other locations (e.g., St. John: median values of 0 to 8 juveniles per $0.25 \mathrm{~m}^{2}$ ), the disturbed characteristics of reefs in the Florida Keys (Porter \& Meier 1992, Chiappone \& Sullivan 1997), and the largely unexplored effects of disturbance on coral reproduction and recruitment. Additionally, Chiappone \& Sullivan (1996) quantified adult corals as the number of colonies by species but, in the present study, percentage cover of all scleractinians was used. Percentage cover was used because colony size (i.e., area) is thought to be related positively to fecundity in scleractinians (Jackson 1979). Therefore, area arguably is more germane than abundance for a test of the hypothesis that adult corals produce the larvae that recruit to nearby areas. However, neither colony area nor abundance may be appropriate to test this hypothesis, as fecundity can vary widely among coral colonies
(Harrison \& Wallace 1990). Indeed, recent studies on the Great Barrier Reef, Australia, have demonstrated that most $(72 \%)$ of the variation in recruitment of acroporids can be explained by variation in fecundity (Hughes et al. in press), and the density of adult and juvenile corals typically are not correlated (Dunstan \& Johnson 1998, Hughes et al. 1999, in press). Together with the present results, these findings suggest that spatial variation in coral community structure is not driven linearly by the contemporaneous distribution of juvenile corals, and vice versa. This does not challenge the role of recruitment in mediating adult population structure (Caley et al. 1996) but suggests, instead, that more complex experimental designs will be necessary to describe the possibly non-linear relationships between coral community structure and coral recruitment (Petraitis \& Latham 1999).

One explanation for the distribution of juvenile corals in St. John is that it is a result of the interaction between larval supply and hydrographic effects (Black et al. 1991, Caley et al. 1996, Caselle \& Warner 1996). However, the quantification of several-year-old juveniles rather than newly settled corals increases the likelihood that post-settlement events also were important in creating the observed patterns. For example, immediate post-settlement differences in growth and mortality could generate among-site variation in the density of juvenile corals, even if the initial rates of recruitment were similar. Alternatively, post-settlement events could smooth the effects of among-site differences in recruitment, as occurs on the Great Barrier Reef (Dunstan \& Johnson 1998). Although these hypotheses cannot be tested unless newly settled corals are monitored, insight into the roles of post-settlement events can be obtained by monitoring juvenile corals. Such an analysis in St. John did not detect significant among-site differences in growth rates and, while mortality varied among sites, it was not correlated with the density of juvenile corals. In other words, mortality appeared to be density-independent for juvenile corals. Thus, it is concluded that early lifehistory events (as opposed to immediate post-settlement processes) are unlikely to account for the spatial variation in the distribution of juvenile corals in St. John. Although working with newly settled corals, Hughes et al. (1999) concluded similarly that most of the variation in patterns of recruitment occurred at the time of settlement. However, the conclusions from the present study should be interpreted with caution for several reasons: (1) it is unknown how the growth and mortality of juvenile corals vary from year to year, and how (or whether) this influences the relationship between adult and juvenile corals. Annual variation in growth and mortality provide potentially important mechanisms contributing to the temporal variation in 
the population of juvenile corals in St. John (Fig. 3), and experiments to quantify this effect are currently underway. Regardless of the outcome, the paucity of information on post-settlement events in scleractinians (but see Smith 1992, Dunstan \& Johnson 1998) makes the study of these processes a research priority. (2) The findings of this study are influenced strongly by the taxonomic composition of the population of juvenile corals surveyed. Thus, the majority of juveniles belonged to the same small group of species that are numerically dominant as recruits throughout the Caribbean (Bak \& Engel 1979, Chiappone \& Sullivan 1996), but rarely (if at all) have important roles in reef construction (Sheppard 1982). Moreover, at least 2 species - Favia fragum and Siderastrea radians - can reach sexual maturity within the size range defined here as juvenile (Soong 1993), and this could influence their growth and mortality. For example, sexual maturity might explain why mortality of $F$. fragum apparently is affected by site-specific effects. (3) As discussed below, the shallow reefs of St. John are not representative of all Caribbean reefs, particularly those in deeper water.

The present conclusions are similar to those emerging from studies of coral reefs and coral recruitment on the Great Barrier Reef (Dunstan \& Johnson 1998, Hughes et al. 1999, in press). Namely that the density of coral recruits differs markedly over spatial and temporal scales and is incongruent with the abundance of adult corals. Thus, Caribbean reefs, like those of the Great Barrier Reef, probably differ from each other in dynamics and turnover of scleractinians, so that current state need not predict current dynamics (after Sale 1999), and community stability can obscure demographic turmoil (Hughes 1996). The similarities in the results from St. John and the Great Barrier Reef are evident despite biogeographic differences in the reproduction and recruitment of corals (Richmond \& Hunter 1990, Smith 1992) as well as methodological differences among studies. For example, most Pacific corals are synchronous, broadcast-spawners with longlived dispersive larvae (Harrison \& Wallace 1990, Richmond \& Hunter 1990), while most Caribbean corals are asynchronous brooders that produce larvae capable of settling shortly after release (Harrison \& Wallace 1990, Richmond \& Hunter 1990). Additionally, the present study focuses on juvenile corals rather than newly settled corals (cf. Dunstan \& Johnson 1998), and addresses a spatial scale that is $>2$ orders of magnitude smaller than the largest scale being investigated on the Great Barrier Reef (Hughes et al. 1999). The spatial variation in St. John is comparable to the among-site, within-reef variation of Hughes et al. (1999), and demonstrates that shallow Caribbean reefs display the vagaries of recruitment expected from an open system
(Caley et al. 1996). These results raise the possibility that similar mechanisms may be affecting coral population structure in St. John and on the Great Barrier Reef. Testing this hypothesis will be difficult because of biogeographic differences in coral abundance, diversity and recruitment, but comparative studies of the population biology of genera common to both locations (e.g., Porites) could be a valuable approach.

This study examines possible mechanisms affecting patterns of coral reef community structure in St. John. Whether or not the results have general application depends on the extent to which the reefs of St. John are representative of other locations. The shallow reefs of St. John are different from those in deeper water throughout the Caribbean (e.g., Goreau 1959), notably in the large amounts of hard substratum (i.e., vacant space and algal turf) that facilitates coral recruitment (Connell et al. 1997), and their frequent exposure to storm damage. However, their community structure is broadly similar to reefs at similar depths throughout the northeastern Caribbean (Edmunds et al. 1990), the central Bahamas (Chiappone et al. 1997), and the Florida Keys (Chiappone \& Sullivan 1997). Moreover, the dominant recruiting coral species in St. John are the same species that dominate recruiting coral populations throughout the Caribbean (Bak \& Engel 1979, Smith 1997); even the paucity of juveniles of reefbuilding taxa such as Montastraea spp. in St. John is well known from other locations (Bak \& Engel 1979, Rylaarsdam 1983, Hughes 1985). There is less consensus, however, on the quantitative aspects of coral recruitment. For example, in comparison to St. John, the density of Porites sp. juveniles was 10-fold higher in Bermuda (for P. astreoides, Smith 1992), coral mortality was $41 \%$ lower in Bermuda (calculated for $P$. astreoides, Smith 1992), and the overall growth rate of juveniles was 12-fold higher in Curaçao (van Moorsel 1988). The causes for these regional differences in density, mortality, and growth rates of juvenile corals are a matter of speculation, but they may be mediated by algal turf and macroalgae. These functional groups of algae occupy large amounts of substratum on the shallow reefs of St. John (e.g., Fig. 2; also Rogers et al. 1997), and the Caribbean as a whole (Hughes 1994, Chiappone et al. 1997), they vary temporally in cover (Rogers et al. 1991, 1997), and are known to mediate the success of coral recruits (Birkeland et al. 1981, Hughes 1989).

Acknowledgements. This research was made possible by the long-term support and encouragement of Dr Caroline Rogers through the Coral Reef Assessment Program of the Virgin Islands National Park. I would like to thank E. D. Keach, C. Zilberberg, D. W. Swanson and S. V. Vollmer for support in the field, and J. F. Bruno, M. Calavetta, D. J. Gardella and D. W. Swanson for assistance analyzing the data. Comments 
from J. F. Bruno, R. C. Carpenter, S. V. Vollmer, C. Zilberberg and 3 anonymous reviewers improved earlier drafts of this paper. Our visits to the Virgin Islands Environmental Resources Station were made productive and enjoyable through the hard work and enthusiasm of C. Grippaldi, V. Powell and E. Clendenon. Financial support was made available through the Coral Reef Assessment Program of the Virgin Islands National Park, the Research, Scholarship and Creative Activity Awards program of California State University Northridge and, in part, through a grant from the Office of Naval Research (N00014-93-1-0440).

\section{LITERATURE CITED}

Aronson RB, Precht WF (1995) Landscape patterns of reef coral diversity: a test of the intermediate disturbance hypothesis. J Exp Mar Biol Ecol 192:1-14

Aronson RB, Precht WF (1997) Stasis, biological disturbance and community structure of a holocene coral reef. Paleobiology 23:326-346

Aronson RB, Precht WF (in press) Evolutionary paleoecology of Caribbean coral reefs. In: Allmon WD, Bottjer DJ (eds) Evolutionary paleoecology: the ecological context of macroevolutionary change. Columbia University Press, New York

Babcock R (1989) Fine-scale spatial and temporal patterns in coral settlement. Proc 6th Int Coral Reef Symp 2:635-639

Babcock R, Mundy C (1996) Coral recruitment: consequences of settlement choice for early growth and survivorship in two scleractinian corals. J Exp Mar Biol Ecol 206:179-201

Bak RPM, Engel MS (1979) Distribution, abundance and survival of juvenile hermatypic corals (Scleractinia) and the importance of life history strategies in the parent community. Mar Biol 54:341-352

Bak RPM, Meesters EH (1999) Population structure as a response of coral communities to global change. Am Zool 39:56-65

Birkeland C, Rowley D, Randall RH (1981) Coral recruitment patterns at Guam. Proc 4th Int Coral Reef Symp 2:339-344

Black KP, Moran PJ, Hammond LS (1991) Numerical models show coral reefs can be self-seeding. Mar Ecol Prog Ser 74:1-11

Bythell JC, Gladfelter EH, Bythell M (1993) Chronic and catastrophic natural mortality of three common Caribbean reef corals. Coral Reefs 12:143-152

Caley MJ, Carr MH, Hixon MA, Hughes TP, Jones GP, Menge BA (1996) Recruitment and the local dynamics of open marine populations. Annu Rev Ecol Syst 27:477-500

Carlon DB, Olson RR (1993) Larval dispersal distance as an explanation for adult spatial patterns in two Caribbean reef corals. J Exp Mar Biol Ecol 173:247-263

Carleton JH, Sammarco PW (1987) Effects of substratum irregularity on success of coral settlement: quantification by comparative geomorphological techniques. Bull Mar Sci 40:85-98

Caselle JE, Warner RR (1996) Variability in recruitment of coral reef fishes: the importance of habitat at two spatial scales. Ecology 77:2488-2504

Chiappone M, Sullivan KM (1996) Distribution, abundance and species composition of juvenile scleractinian corals in the Florida reef tract. Bull Mar Sci 58:555-569

Chiappone M, Sullivan KM (1997) Rapid assessment of reefs in the Florida Keys: results from a synoptic survey. Proc 8th Int Coral Reef Symp 2:1509-1514

Chiappone M, Sullivan KM, Sluka R (1997) Status of reefs in the central Bahamas on a large-scale survey. Proc 8th Int Coral Reef Symp 1:345-350
Coffroth MA, Mulawka JM (1995) Identification of marine invertebrate larvae by means of PCR-RAPD species-specific markers. Limnol Oceanogr 40:181-189

Connell JH (1973) Population ecology of reef-building corals In: Jones OA, Endean R (eds) Biology and geology of coral reefs, Vol 2. Academic Press, New York, p 205-245

Connell JH (1978) Diversity in tropical rain forests and coral reefs. Science 199:1302-1310

Connell JH, Keough MJ (1985) Disturbance and patch dynamics of subtidal marine animals on hard substrata. In: Pickett STA, White PS (eds) The ecology of natural disturbance and patch dynamics. Academic Press, New York, p 125-151

Connell JH, Hughes TP, Wallace CC (1997) A 30-year study of coral abundance, recruitment, and disturbance at several scales in space and time. Ecol Monogr 67:461-488

Dunstan PK, Johnson CR (1998) Spatio-temporal variation in coral recruitment at different scales on Heron Reef, southern Great Barrier Reef. Coral Reefs 17:71-81

Ebert TA (1999) Plant and animal populations. Academic Press, San Diego

Edmunds PJ, Bruno JF (1996) The importance of sampling scale in ecology: kilometer-wide variation in coral reef communities. Mar Ecol Prog Ser 143:165-171

Edmunds PJ, Roberts DA, Singer R (1990) Reefs of the northeastern Caribbean. I. Scleractinian populations. Bull Mar Sci 46:780-789

Fadlallah YH (1983) Sexual reproduction, development and larval biology in scleractinian corals. Coral Reefs 2: 129-150

Gaines SD, Bertness MD (1992) Dispersal of juveniles and variable recruitment in sessile marine species. Nature 360:579-580

Gaines SD, Bertness MD (1993) The dynamics of juvenile dispersal: why field ecologists must integrate. Ecology $74: 2430-2435$

Gaines SD, Denny MW (1993) The largest, smallest, highest, lowest, longest, and shortest: extremes in ecology. Ecology 74:1677-1692

Gaines S, Roughgarden J (1985) Larval settlement rate: a leading determinant of structure in an ecological community of the marine intertidal zone. Proc Natl Acad Sci USA 82:3707-3711

Ginsburg RN (Compiler) (1994) Proceedings of the Colloquium of Global Aspects of Coral Reefs: health, hazards and history, 1993. Rosenstiel School of Marine and Atmospheric Science, University of Miami

Goreau TF (1959) The ecology of Jamaica coral reefs: species composition and zonation. Ecology 40:67-90

Gosselin LA, Qian PY (1997) Juvenile mortality in benthic marine invertebrates. Mar Ecol Prog Ser 146:265-282

Grigg RW, Dollar SJ (1991) Natural and anthropogenic disturbance on coral reefs. In: Dubinsky Z (ed) Ecosystems of the world, Vol 25. Coral reefs. Elsevier, New York, p 439-452

Hanski I (1997) Metapopulation dynamics: from concepts and observations to predictive models. In: Hanski IA, Gilpin ME (eds) Metapopulation biology. Academic Press, San Diego, p 69-91

Harrison PL, Wallace CC (1990) Reproduction, dispersal and recruitment of scleractinian corals. In: Dubinsky Z (ed) Ecosystems of the world, Vol 25. Coral reefs. Elsevier, New York, p 133-207

Hughes TP (1985) Life histories and population dynamics of early successional corals. Proc 5th Int Coral Reef Symp 4:101-106

Hughes TP (1989) Community structure and diversity of coral reefs: the role of history. Ecology 70:275-279 
Hughes TP (1994) Catstrophies, phase shifts, and large scale degradation of a Caribbean coral reef. Science 265: $1547-1551$

Hughes TP (1996) Demographic approaches to community dynamics: a coral reef example. Ecology 77:2256-2260

Hughes TP, Connell JH (1999) Multiple stressors on coral reefs: a long-term perspective. Limnol Oceanogr 44: 932-940

Hughes, TP, Baird, AH, Dinsdale EA, Moltschaniwskyj NA, Pratchett MS, Tanner JE, Willis BL (1999). Patterns of recruitment and abundance along the Great Barrier Reef. Nature 397:59-63

Hughes TP, Baird AH, Dinsdale EA, Moltschaniwskyj NA, Pratchett MS, Tanner JE, Willis BL (in press) Supply-side ecology works both ways: the link between benthic adults, fecundity and larval recruits. Ecology

Jackson JBC (1979) Morphological strategies of sessile animals. In: Larwood G, Rosen BR (eds) Biology and systematics of colonial organisms. Academic Press, London p 499-555

Jackson JBC (1992) Pleistocene perspectives on coral reef community structure. Am Zool 31:719-731

Jackson JBC, Budd AF, Pandolfi JM (1997) The shifting balance of natural communities. In: Jablonski D, Erwin DH, Lipps JH (eds) Evolutionary paleobiology. University of Chicago Press, Chicago, p 89-121

Johnson KG (1992) Population dynamics of a free living coral: recruitment, growth and survivorship of Manicina areolata (Linnaeus) on the Caribbean coast of Panama. J Exp Mar Biol Ecol 164:171-191

Karlson RH, Cornell HV (1998) Scale-dependent variation in local vs regional effects on coral species richness. Ecol Monogr 68:259-274

Karlson RH, Hurd LA (1993) Disturbance, coral reef communities, and changing ecological paradigms. Coral Reefs 12: $117-126$

Keough MJ, Black KP (1996) Predicting the scale of marine impacts: understanding planktonic links between populations. In: Schmitt RJ, Osenberg CW (eds) Detecting ecological impacts. Academic Press, San Diego, p 199-234

Knowlton N (1992) Thresholds and multiple stable states in coral reef community dynamics. Am Zool 32:674-682

Levin SA (1992) The problem of pattern and scale in ecology. Ecology 73:1943-1967

Morse DEN, Hooker N, Morse ANC, Jensen RA (1988) Control of larval metamorphosis and recruitment in sympatric agaricid corals. J Exp Mar Biol Ecol 116:193-217

Mumby PJ (1999) Can Caribbean coral populations be modelled at metapopulation scales? Mar Ecol Prog Ser 180: 275-288

Pandolfi JM (1996) Limited membership in Pleistocene reef coral assemblages from the Huon Peninsula, Papua New Guinea: constancy during global change. Paleobiology 22:152-176

Petraitis PS, Latham RE (1999) The importance of scale in testing the origins of alternative community states. Ecology 80:429-442

Porter J, Meier O (1992) Quantification of loss and change in Floridean reef coral populations. Am Zool 32:625-640

Richmond RH (1997) Reproduction and recruitment in corals: critical links in the persistence of reefs. In: Birkeland C (ed) Life and death of coral reefs. Chapman \& Hall, New York, p 175-197

Richmond RH, Hunter CL (1990) Reproduction and recruitment of corals: comparisons among the Caribbean, the tropical Pacific and the Red Sea. Mar Ecol Prog Ser 60: 185-203
Rogers CS (1993) Hurricanes and coral reefs: the intermediate disturbance hypothesis revisited. Coral Reefs 12:127-138

Rogers CS, Teytaud R (1988) Marine and terrestrial ecosystems of the Virgin Islands National Park and Biosphere Reserve. Biosphere Reserve Rep 29:1-112

Rogers CS, Fitz HC, Gilnack M, Beets J, Hardin J (1984) Scleractinian coral recruitment patterns at Salt River Submarine Canyon, St. Croix, US Virgin Islands. Coral Reefs 3:69-76

Rogers CS, McLain LN, Tobias CR (1991) Effects of Hurricane Hugo (1989) on a coral reef in St. John, USVI. Mar Ecol Prog Ser 78:189-199

Rogers CS, Garrison V, Grober-Dunsmore R (1997) A fishy story about hurricanes and herbivory: seven years of research on a reef in St. John, U.S. Virgin Islands. Proc 8th Int Coral Reef Symp 1:555-560

Rylaarsdam KW (1983) Life histories and abundance patterns of colonial corals on Jamaicam reefs. Mar Ecol Prog Ser $13: 249-260$

Sale PF (1999) Recruitment in space and time. Nature 397:25-27

Sheppard CRC (1982) Coral populations on reef slopes and their major controls. Mar Ecol Prog Ser 7:83-115

Smith SR (1992) Patterns of coral recruitment and post-settlement mortality on Bermuda's reefs: comparisons to Caribbean and Pacific reefs. Am Zool 32:663-673

Smith SR (1997) Patterns of coral settlement, recruitment and juvenile mortality with depth at Conch Reef, Florida. Proc 8th Int Coral Reef Symp 2:1197-1202

Sokal RR, Rohlf FJ (1995) Biometry. The principles and practise of statistics in biological research, 3rd edn. WH Freeman \& Co, New York

Soong K (1991) Sexual reproductive patterns of shallowwater reef corals in Panama. Bull Mar Sci 49:832-846

Soong K (1993) Colony size as a species character in massive reef corals. Coral Reefs 12:77-83

Tabachnick BG, Fidell LS (1996) Using multivariate statistics. Harper Collins, New York

Thorson G (1950) Some factors influencing the recruitment and establishment of marine benthic invertebrates. Neth J Sea Res 3:267-293

Tolimieri N, Sale PF, Nemeth RS, Gestring KB (1998) Replenishment of populations of Caribbean reef fishes: are spatial patterns of recruitment consistent through time? J Exp Mar Biol Ecol 230:55-71

van Moorsel GWNM (1988) Early maximum growth of stony corals (Scleractinian) after settlement of artificial substrata on a Caribbean reef. Mar Ecol Prog Ser 50:127-135

van Veghel MLJ (1993) Multiple species spawning on Curaçao reefs. Bull Mar Sci 52:1017-1021

Wallace CC (1985) Seasonal peaks and annual fluctuations in recruitment of juvenile scleractinian corals. Mar Ecol Prog Ser 21:289-298

Weil E, Knowlton N (1994) A multi-character analysis of the Caribbean coral Montastrea annularis (Ellis and Solander, 1786) and its two sibling species, M. faveolata (Ellis and Solander, 1786) and M. franksi (Gregory, 1895). Bull Mar Sci 55:151-175

Woodley JD, Chornesky EA, Clifford PA, Jackson JBC, Kaufman LS, Knowlton N, Lang JC, Pearson MP, Porter JW, Rooney MC, Rylaarsdam KW, Tunnicliffe VJ, Wahle CM, Wulff JL, Curtis ASG, Dallmeyer M, Jupp BP, Koehl MAR, Neigel J, Sides EM (1981) Hurricane Allen's impact on Jamaican coral reefs. Science 214:749-755

Yoshioka PM (1996) Variable recruitment and its effects on the population and community structure of shallow water gorgonians. Bull Mar Sci 59:433-443

Submitted: June 6, 1999; Accepted: January 28, 2000

Proofs received from author(s): July 17, 2000 